\title{
Meaning of home visits to Brazilian health students
}

\begin{abstract}
Background: Home visits have become increasingly widespread in Brazil since the emergence of the Family Health Program. Therefore, it is necessary to develop the professional skills need to conduct these visits during their education.

Objective: The aim of this study was to understand the meaning of home visits to Brazilian health students under the light of the principles of Edgar Morin's Complexity Theory.

Methodology: The Grounded Theory approach was used in this study. Data collection was performed between December 2014 and July 2016 by interviews with students and health professionals who graduated during the previous year and are working in the Public Health System in the South of Brazil.

Results: The students experience an order-disorder-order-(re)organization process. It results from the inter-weaving of three aspects: confrontation with reality, selfreflection and transcending personal limits.

Conclusion: The results of this study show that the process of emotional and professional (re)organization takes the course of order, disorder, order, self-reflection and overcoming limits. The study also reveals that persistence, interactions, dialogue and theoretical discussions during the education program are fundamental to overcome the limits of scientific knowledge and changing personal attitudes towards more solidarity.
\end{abstract}

Keywords: education, learning, home visits, family health strategy
Volume 4 Issue I - 2017

\author{
Dirce Stein Backes,' Leris Haeffner,' Lena \\ Dorin, ${ }^{2}$ Claudia Oetting-Rob, ${ }^{2}$ Marli Stein \\ Backes, ${ }^{3}$ Alacoque Lorenzini Erdmann, ${ }^{3}$ \\ Andreas Büscher ${ }^{2}$ \\ 'Centro Universitário Franciscano-Unifra, Brazil \\ ${ }^{2}$ University of Applied Science Osnabrück and University of \\ Witten/Herdecke, Germany \\ ${ }^{3}$ Universidade Federal de Santa Catarina, Brazil
}

Correspondence: Dirce Stein Backes, Centro Universitário Franciscano-Unifra, Santa Maria, RS, Brazil, Tel 55996418 109, Email backesdirce@unifra.br

Received: September 07, 2017 | Published: October 18, 2017

\section{Introduction}

Responding to the principles and guidelines of the National Health System - Sistema Único de Saúde (SUS), the Primary Health Care in Brazil has been redirected since 1994 and the core Family Health Strategy has been established with the challenge of developing actions focusing on individual family members and collective care for families. ${ }^{1}$ The Family Health Strategy was part of the government's strategy for restructuring the primary health care and the SUS healthcare models. Initially introduced as a vertical program that offered mainly maternal and child health services to more needy or at-risk populations, since 1998 the initiative has been the main strategy for structuring municipal health systems. The Family Health Strategy works through family health-care teams-which are composed of one doctor, one nurse, two auxiliary nurse, and six community health workers-and, since 2004, the Strategy has begun to include oral health teams. Family health teams are located at health units, and are assigned to specific geographical areas and defined populations of 600 - 1000 families. The teams provide a first point of contact with the local health system, coordinate care, and work towards integration with diagnostic, specialist, and hospital care. ${ }^{2,3}$

The Family Health Strategy is actualized through a set of actions and multidisciplinary interventions that aim at meeting individual and family needs. Home visits performed by health are one of the key activities. They are intended to take the families' social contexts into account and to identify the health needs of the families. However, home visits require a more comprehensive view of patients needs than the biomedical model offers that still forms the core of health educational programs. ${ }^{4}$ For the students and their professors this is one of the educational aims to reach.
In the curriculum home visits are considered as an approach that allows the creation of inter subjective perspectives through discussion, dialogue, observation and interpretations. In addition, home visits allow a broader view of the determinants of health and disease and the recognition of individual and collective interactions. Home visits are a way to strengthen the students' communication and professional skills. ${ }^{5-8}$

Several universities in Brazil have developed professional skills by means of home visits in order to contribute to the consolidation of the National Health System. The Health System increasingly requires professionals being able to understand individual and family needs and is capable of investing in health promotion in a unique, comprehensive and multidisciplinary manner. Because of this home visits transcend the current fragmented and punctual assistance provided in the Health System and become part of a Family Health Strategy with a systemic, innovative and entrepreneurial character. ${ }^{6,9}$

The National Curriculum Guidelines for Undergraduate health courses have gradually encouraged home visits by advocating the training of reflective and critical professionals with regard to different dimensions of the health of human beings. The professional profile shall include scientific, intellectual and ethical competencies in order to intervene when families suffer from highly prevalent health problems. Furthermore, the professionals should develop a sense of (social) responsibility. ${ }^{10}$

Based on these guidelines, the undergraduate Health Course at the Franciscan University - Unifra proposed to realize home visits from the third semester. A specific learning concept has been developed for students to gain experiences in home visits. Groups of four to five 
students form a learning unit with a professor. They are attributed to poor families, which they visit at home regularly about every ten days. Students start their projects at the beginning of the third semester and continue through up to the eighth semester. After each visit, these "home visits" are evaluated individually and collectively within their learning unit.

Furthermore, the students' task is to document and reflect their perceptions and experiences through writing a portfolio. Besides integrating their personal views and thoughts regarding their own position and attitude, the students were asked to integrate the perspective of the whole family and different family members into the portfolio. The professors act in a supervising role and steer the process. Some home visit periods can span over one year, some families have been visited for a period of three years or even longer. The object of this approach is to develop communication, solidarity skills. So far only little is known about the student's perceptions about this approach and the way it is being taught. Within the complex Brazilian health system, we consider that any reflection on this subject cannot be analyzed in a linear thinking way, but under multiple dimensions. In this way, we envisage the importance of understanding the interconnections of the points that conform them, theoretical support to the Complexity Theory of Edgar Morin for subsidizing the enlarged look before complex phenomena. ${ }^{11}$

\section{Objective}

The aim of this study was to understand the meaning of home visits to Brazilian health students under the light of the principles of Edgar Morin's Complexity Theory.

\section{Method}

A Grounded Theory and the principles of Edgar Morin's Complexity Theory approach was used in this study. This approach aims at identifying, developing and relating concepts based on data, which was collected, analyzed and compared in a systematic, concomitant manner. The development of a theoretical framework denotes a set of categories, constructed and based on emerging issues and concepts, which indicate relationships that are capable of forming a theoretical explanatory framework of a social phenomenon. ${ }^{12,13}$ Another characteristic of the Grounded Theory approach is the capacity of this method to facilitate the generation of concepts that demonstrate changes over time. ${ }^{14}$

\section{Data collection and analysis}

The study was characterized by simultaneous data collection and analysis, constant comparative analysis, and identification of key social processes. ${ }^{15}$ The data was collected between December 2014 and July 2016 by interviews with health students who had completed two semesters, and health professionals who had graduated during the previous year and were working in the Public Health system.

In compliance with the principle of theoretical sampling the first sample group was created with ten randomly selected students from the fourth semester of the health course who had conducted twelve home visits during the third semester. The home visits begin in the third semester of graduation by visiting families in a poor community as described in a previous study. ${ }^{16}$ The interviews were based on the following questions: What is the meaning of family visits to you? What were the advantages and difficulties that you encountered? The interviews were digitally recorded and transcribed. Data analysis was performed by constant by open coding procedures and constant comparative analyses.

Analysis of the data collected from the first sample group allowed for identifying initial properties and hypotheses, which guided the formation of the second group, comprised of ten students in the last semester of health course. These were selected randomly from the institution's registers and were interviewed, based on the following questions: What contribution did the home visits make to your professional training? Did they make any difference in your academic qualification?

The data from the second group served to deepen the theoretical model, strengthen the categories created after analysis of the first group's data and provided supplementary information that indicated the characteristics of the qualification within the context of health. Therefore, it was decided to conduct a third set of interviews, with seven health professionals who volunteered to participate these working in the Public Health System. They were asked: Which were the contributions of the home visits to your professional life? What were the contributions to implementing the Health System?

The empirical data was analyzed based in the process of open, axial and selective coding. ${ }^{15}$ The codes were organized according to their respective similarities and differences, and were grouped into categories and subcategories. A central category was defined, based on the analysis of the relationships between the categories. After structuring the theoretical model, which represented the connection between the categories and subcategories, it was validated.

For the validation and explanatory description of the theoretical model constructed, it was presented to six of Unifra's health teachers. They evaluated the theoretical model and presented suggestions that were incorporated into this model.

\section{Ethical considerations}

The study was approved by the Research Ethics Committee of the Franciscan University (Protocol Number 1.641.967/2014). In accordance with the protocol of the Brazilian National Health Council on Research in Human Subjects, the principal investigator discussed the study design and objectives with participants, obtained their voluntary consent, and ensured participant confidentiality and data protection.

\section{Findings}

The theoretical model of the meaning of home visits to health students can be conceptualized as an order-disorder-order (re) organization process. The effect of the twelve visits per semester, with the duration of two hours each, is transcended the personal limits. Initially the students demonstrated anxiety, uncertainty, disappointment and frustration. To the extent to which they take up the challenge, the students rethink values, concepts, and practices and plan new strategies. On completion of the activity proposed, the students demonstrated personal overcoming and recognized that they made the difference in the families' lives.

\section{Home visits for students}

The process of "Experiencing an order-disorder-order-(re) organization process" results from the integration of three different aspects: (I) Confrontation with reality, (II) Self-reflection, and (III) Transcending personal limits. The content of each of these three categories, resulting from the organization and grouping of their respective codes and subcategories, will be presented below. 


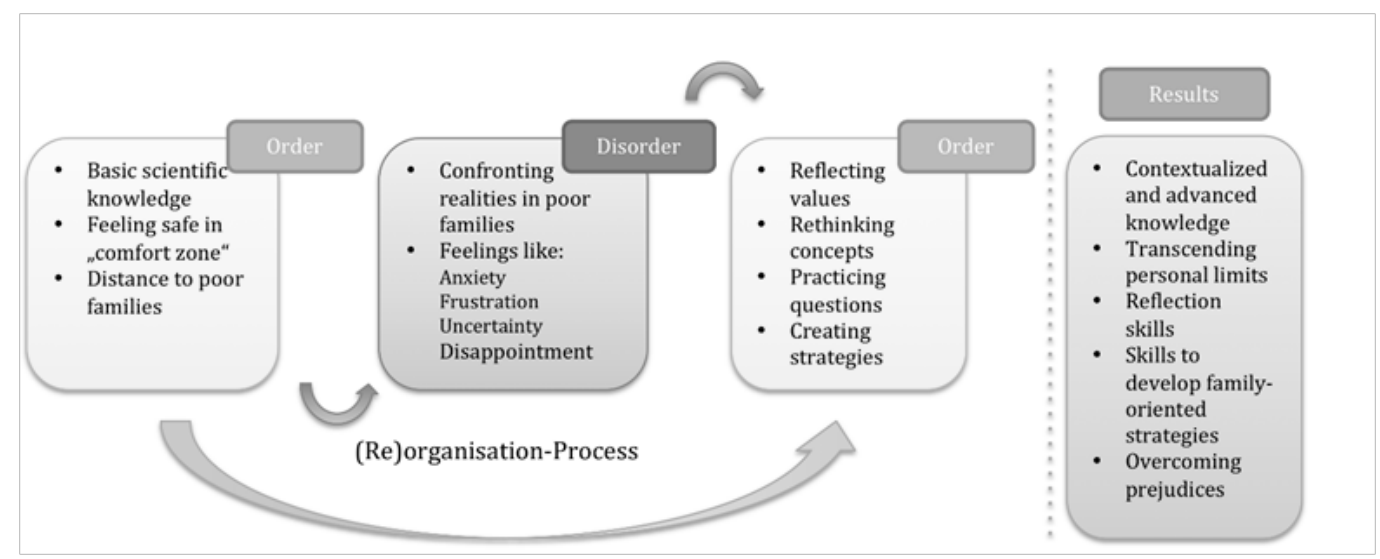

Figure I Experiencing an order-disorder-order (re)organization process.

\section{Confrontation with reality}

During the first family visits, at all times under professor's supervision, students experienced intense personal disorder. The disorder came accompanied by anxiety, uncertainty, disappointments and frustrations resulting from the reality they found. For many students, this was the first contact with poor families and communities. The families were chosen by the Family Health Strategy team because they were living under conditions of extreme poverty.

During some moments, the students felt as though their "hands were tied" and they did not "know where to start", because they found a reality for which they had no answers at hand. Many were disappointed, cried and became thoughtful. Others experienced a feeling of powerlessness. During the first visits I felt as though my hands were tied. I was frustrated. I never expected to find so much poverty. I didn't know where to start. I thought that our visits would be of no use whatever. But in the end, we became aware of the developments that had happened (P2).

Because they had the appropriate basic knowledge, the students understood that they were going to visit the family to "bring much knowledge" and cause important changes. From the student's early understanding, they thought that the poor families did not have enough knowledge and information. This perception, however, changed after the first visits, when they concluded that they would learn a great deal more than they would teach.

On the first visit, I thought that I would teach the families much knowledge. But I soon noticed that they had information about everything. I was disappointed and didn't know what to do. Many times I thought: They do many things that I do not do in my home. They collect rain water, recycle garbage and many other things (P21).

\section{Self-reflection}

After the initial contact with the families' reality, the students understood that they could also learn from the families. Often they were thoughtful or heard the stories of the families' lives. They noted that despite all the problems, the families lived happily and always found "a way out" of their many difficulties. From this moment on, the students began to develop a self-reflection process with regard to values, concepts, attitudes and practices. Thus, the students began to recognize and positively evaluate the experiences with families, as illustrated in this statement: Many times I became thoughtful... with all the problems the families were always happy and we sometimes complain about small things. I was amazed to see how the families live and how they organize themselves under these conditions. This experience took me out of my comfort zone (P14).

On the other hand, the experience was not limited to the scope of the families, but allowed reflections later, in their own homes, in the classroom, as well as in different spaces and environments. Some students reported that they remembered the families at all times and that sometimes they would wake up at night with the feeling that families could be feeling cold, hungry or experienced some other kind of discomfort. In two cases, more specifically, the students managed to include their own families and overcome the boundaries between poor and wealth that still exists, as shown in the following reports: Every night when I lay down to sleep I remembered... How were things going with these families? The house has so many gaps... wind and cold air coming in everywhere. Would they be able to sleep? When I told my mother, she was so impressed that she went there and brought some things for them (P8).

The reflexive discussion with the teachers and contextualizing as well as theorizing in classroom allowed students to rethink concepts and develop family-centered strategies, in order to accept and understand the reality of each family. During the course of the visits the students began to observe and slowly perceived that the health problems were related not only to the physiological dimension of health, but that they needed to expand their field of vision to include other dimensions. During a short period of time the students were aware of the need of the family to be seen and heard. During the first few visits we went there and did not know what to do. The family did not have any health problems... When we spoke to the teacher, she made us think and look at the surroundings. Little by little we began to perceive that they did not have any apparent disease but an intense need to talk. They never stopped talking. They always waited for us to tell us all about their lives. It was then that we discovered that they needed to be heard (P27).

\section{Transcending personal limits}

The home visits provided several opportunities for development, for both the students and the families. For students the home visits meant overcoming personal limits, professional growth, in addition to lessons learned in life that could not be translated into words, as shown by the following reports:

It was a great challenge to overcome prejudices. I think that was the greatest aim. The feeling that remained, was that of a great 
lesson learned in life and personal and professional growth. Today we understand that the health concept goes beyond physical illness.. (P9). Home visits also had a great impact on the families. For some families, the home visits by the students represented joy and celebration. For others, they meant interest and attention, and to many other students the visits caused dreams and gave new meanings to life. Some families did everything to clean and organize the house to welcome the students, and others counted the days until the students' next home visit.

In one family, the children no longer visited their parents. With our presence, the children began to come back. I think that they were touched by the fact that we showed an interest in their parents (P10). When we arrived at the family home, the children immediately asked us when the next visit will be. They were so happy with our visits that they did not know what to do first to please us. The visits had the character of coexistence and sharing (P16).

As found out by the students, the first visits also generated a kind of discomfort and insecurity for some families. Over the course of time, both students and families needed to overcome prejudices and transcend personal boundaries. The students recognized that despite a certain barrier between the two realities the affiliation was essential. With this the families would open up to speak about their needs. The students also recognized that the bond would develop gradually from reception, dialogue and meaningful exchanges.

During the first visits, the woman always said that all was well. But as we formed the affiliation, she gradually began to open up, and told us that her husband beats her frequently. She said: "I was disheartened... I had no motivation to continue living. You brought back my enthusiasm. Today I have a new incentive to continue living" (P18).

The learning process of the student is a reorganization process. They start with their basic scientific knowledge and feel safe in their comfort zone. From their experiences in their life so far they feel a distance to poor families. Through the confrontation with the realities they are in disorder and feelings like anxiety, uncertainty and deception develop. They reflect their values and rethink their concepts and create strategies to deal with the situations. With this coping strategies they reach a new order. As a result they can contextualize knowledge and transcend their personal limits. The family oriented perspective they developed helps to overcome prejudices they might had before.

\section{Discussion}

\section{Home visits and educational relevance}

The home visits made by students under the professor's supervision should be considered as a sustainable experience and one that stimulated personal and professional reflections. This study shows that home visits go along with a meaningful process of learning and a development of students' sensitivity towards the study object, the family. The students can transfer their experience to their own development, as reported by a student: "I developed a professional attitude at the university, but among the poor families I developed personality". Similar results were found in another study that proposed to analyze home visits made by first-year medical and health students, seen from the viewpoint of family health unit users. ${ }^{17}$

With regard to the personal dimension, the students were confronted with their own limitations and the gaps in their scientific knowledge.
From contact with poor families, students began to develop their personality, not as persons with knowledge superior to that of the families, but as those with a different background. As they became aware of this reality, they found strategies for reception, dialogue and meaningful exchanges. Similar results were found in another study that broadened the discussion by arguing that home visits favor human, creative, and sensitive caring, far beyond hospitality. ${ }^{18}$

Home visits also contributed to personal and professional growth. By overcoming prejudices and developing self-critical reflection skills, the students were able to rethink values, expand concepts and develop health promotion strategies. Another study showed that when academic activities were complemented with family home visits, students became sensitized, more reflexive, which increased their motivation and activated their willingness to learn meaningfully. ${ }^{19}$ Based on these results, it can be argued that the success of the Family Health Strategy team interventions partly depends on the qualification of the professionals involved, resulting from relevant interchanges. These experiences, however, need to be accompanied by theoretical discussions, in order to deepen and broaden the health concepts focusing the individual, family and community perspective.

Another study confirms that the Family Health Strategy presupposes home visit as an interactive and associative innovation in health care. One of the main results is the inter subjective dimension, since the success of health care practices depends not only on the innovative component, but other processes based on approximation, dialogue, and affiliations between professionals, users and services. ${ }^{20}$ Several other studies are based on home visits with a disease and curative focus. ${ }^{6,21-24}$ This study has a broader perspective-a family health focus including the promotion of autonomy and co-responsibility. This leads to inter subjectivity connecting the student's perspective with the family lives.

This perspective fits the development in Brazilian Health Politics to change the focus from an illness-based to an individual and family focus. For these strategies the competencies developed by the students are essential. Thus, the home visits have shown to be a relevant element for making health promotion feasible, as they guide future nurses into real world social scenarios. ${ }^{25}$ Although it is not a new approach in the field of Brazilian Public Health, the home visits occupy an increasingly important space. With the implementation of the Family Health Strategy, the home visit began to be an instrument that establishes personal relations, qualified listening, affiliation and reception. This practice strengthens families to become protagonists in the production of their health. ${ }^{26}$

Finally, the experience contributed to the critical development of the students. Other studies show the need of contemporary education including the active engagement of students, interaction styles, and a commitment to reflective practice in social scenarios. Critical thinking as well as reflection aims at improving practice skills in different contexts. Through the use of critical thinking, nursing students will demonstrate greater independence of mind, intellectual curiosity, courage, humility, empathy and perseverance..$^{27-29}$

\section{Conclusion}

The connection between the assumptions of the meaning of home visits and the principles of Complexity Theory suggest the possibility to deepen the understanding and the difficulties and recognize that the professional (re)organization goes through the stages of order, disorder, order, self-reflection and of overcoming limits and improving 
scientific knowledge. In addition, the study demonstrates that the persistence, interactions, dialogue and theoretical discussions under the supervision of a professor, were essential for transcending the perceptions and for the development of the inter-subjective dimension. The experience has shown that home visits are considered an important approach for understanding and caring for the population's health requirements. Therefore, they must be a part of the health professionals' education. The home visit is, in short, an innovative teaching and learning method that can contribute to the development of relational and social skills, and policies for consolidation of the Brazilian Health System.

For the National Health System including Primary Care it is essential that the Family Health Strategy combines professional health development through improving scientific knowledge and gaining personal experiences to create a suitable reflected attitude with a high appraisal for the families. The limited research in this field is represented in only a few published studies, which could be included. To fit the relevance of home visits, further research with the family focus is essential.

\section{Study limitations}

There are two limitations that need to be acknowledged and addressed with regard to the present study. The first limitation was related to translations from Portuguese to English. The primary researcher, a Portuguese speaker, conducted many of the interviews and is familiar with the context of Brazilian home visits. The second limitation concerns the small sample. We recognize that the number of participants is too limited for broad generalizations. However, the solid evidence gathered through the in-depth interviews allowed us to describe the overall experiences of this learning process, so that education and research professionals can benefit from the findings. Further empirical evaluations, however, are needed to replicate the findings in different contexts.

\section{Acknowledgements}

None.

\section{Conflict of interest}

The author declares no conflict of interest.

\section{References}

1. Giovanella L, Mendonça MHM, Almeida PF. Saúde da Família: limites e possibilidades para uma abordagem integral de atenção primária à saúde no Brasil. Ciência Saude Coletiva. 2009;14(3):783-794.

2. Paim J, Travassos C, Almeida C, et al. The Brazilian health system: history, advances, and challenges. Lancet. 2011;377(9779):1778-1797.

3. Victora CG, Barreto ML, Monteiro CA, et al. Health conditions and health-policy innovations in Brazil: the way forward. Lancet 2011;377(9782):2042-2053.

4. Oliveira MAC, Pereira IC. Primary health Care essential attributes and the family health strategy. Revista Brasileira Enfermagem. 2013;66:158164.

5. Kemp L, Harris E. The challenges of establishing and researching a sustained nurse home visiting programme within the universal child and family health service system. Journal of Research in Nursing. 2012;17(2):127-138.

6. Lopes WO, Saupe R, Massaroli A. Visita domiciliar: tecnologia para o cuidado, o ensino e a pesquisa. Ciência Cuidado Saúde. 2008;7(2):241247.
7. Zeanah PD, Larrieu JA, Boris NW, et al. Nurse home visiting: perspectives from nurses. Infant Ment Health J. 2006;27(1):41-54.

8. Sweet MA, Appelbaum MI. Is Home Visiting an effective strategy? A Meta-Analytic Review of home visiting programs for families with young children. Child Development. 2004;75(5):1435-1456.

9. Backes DS, Erdmann AL. Education of nurses under the social enterprising view. Rev Gaucha Enferm. 2009;30(2):242-249.

10. Fernandes JD, Rebouças LC. A decade of National Curriculum Guidelines for Graduation in Nursing: advances and challenges. Rev Bras Enferm. 2013;66:95-101.

11. Morin E. Introdução ao pensamento complexo. 4th Ed. Porto Alegre (RS), Sulina, Brazil: Springer; 2011

12. Strauss A, Corbin J. Basics of qualitative research: grounded theory procedures and techniques. Thowand Lage Daks, Brazil: Lage Publications; 1990.

13. Strauss A, Corbin J. Pesquisa qualitativa: técnicas e procedimentos para o desenvolvimento de teoria fundamentada. Porto Alegre, Brazil: Artmed; 2008.

14. Richards L, Morse JM. Readme first for a user's guide to qualitative methods. Thousand Oaks, CA, USA: SAGE; 2007.

15. Charmaz K. Constructing grounded theory: A practical guide through qualitative analysis. Thousand Oaks, CA, USA: SAGE; 2006.

16. Backes DS, Grando MK, Gracioli MA, et al. Theoretical and practical experience with an innovative approach to nursing education. Revista Anna Nery. 2012;16(3):597-602.

17. Marin MJS. The meaning of home visits conducted by medicine and nursing students: a qualitative study with users of family health units. Cien Saude Colet. 2011;16(11):4357-4365.

18. Nascimento KC, Virgílio MS, Mendonça RS, et al. Visita à família em seu domicílio: uma possibilidade de cuidado que ultrapassa os limites do biológico. Nursing. 2002;5(52):123-129.

19. Cardenas LAG, Kambourov M, Arango LZ, et al. Impacto da visita domiciliar familiar na aprendizagem dos alunos de graduação em Medicina e na área de Pediatria Social. Interface. 2013;17(46):649-660.

20. Albuquerque ABB, Bosi MLM. Home visits as a component of the Family Health Program: user's perceptions in Fortaleza, Ceara State, Brazil. Cadernos de Saúde Pública. 2009;25(5):1103-1112.

21. Cowley S. Home visitors and child health in England: advances and challenges. Rev Esc Enferm USP. 2011;45(2):1810-1816.

22. Kerber NPC, Kirchhof ALC, Cezar-Vaz MR. Home care assistance and the right to health: an experience in the Brazilian net. Acta paulista enfermagem. 2010;23(2):244-250.

23. Cruz MM, Bourget MM. Home visiting in the family health strategy: investigating families' perceptions. Saúde Sociedade. 2010;19(3):605613.

24. Sakata KN, Almeida MCP, Alvarenga AM, et al. Concepções da equipe de saúde da família sobre as visitas domiciliares. Revista Brasileira Enfermagem. 2007;60(6):659-664.

25. Santos EM, Kirschbaum DIR. The historical trajectory of the domiciliary visiting in Brazil: a bibliography revision. Revista Eletrônica de Enfermagem. 2008;10(1):220-227.

26. Matias SS, Pereira AAM. Visita domiciliar: (re)significando a prática dos profissionais da estratégia de saúde da família. Ciência Cuidado Saúde. 2010;7(4):244-252.

27. Simpson E, Courtney MD. Critical thinking in nursing education: a literature review. Int J Nurs Pract. 2002;8(4):89-98. 
28. Mangena A, Chabeli MM. Strategies to overcome obstacles in the facilitation of critical thinking in nursing education. Nurse Educ Today. 2005;25(4):291-298
29. Horsfall J, Cleary M, Hunt GE. Developing a pedagogy for nursing teaching-learning. Nurse Educ Today. 2012;32(8):930-933. 